\title{
Respiration uncoupling and metabolism in the control of energy expenditure
}

\author{
Daniel Ricquier \\ Centre National de la Recherche Scientifique Unit 9078; Faculty of Medicine Necker-Enfants Malades, Paris, France
}

\begin{abstract}
Metabolic energy expenditure negatively regulates energy balance. Metabolic and catabolic pathways contribute to energy expenditure. Catabolic pathways split C-containing molecules into small molecules and generate reduced coenzymes and ATP. For a given amount of substrate, any increase in energy expenditure requires either increased ATP hydrolysis or decreased ATP synthesis. In skeletal muscles substrate utilisation is coupled to ATP production, whereas ATP hydrolysis is activated during physical exercise and increases energy expenditure. In brown adipose tissue activation of cells during exposure to cold increases substrate utilisation in such a way that glucose and fatty acid oxidation detach from the orthodox coupling to ATP synthesis and result in thermogenesis. The unique mechanism of uncoupling respiration that occurs in brown adipocyte mitochondria represents an attractive strategy for promoting energy expenditure and decreasing the fat content of the body. Moreover, ectopic expression of brown fat uncoupling protein (UCP) 1 in mouse skeletal muscle and induction of UCP1 in mouse or human white adipocytes promote fatty acid oxidation and resistance to obesity. In normal conditions UCP2 and UCP3 do not seem to contribute substantially to energy expenditure. Whether the induction of UCP1, the induction of other UCP or chemical mild uncoupling represent promising strategies for attenuating nutrient efficiency and counteracting obesity should be considered.
\end{abstract}

Respiration uncoupling: Energy expenditure: Uncoupling protein 1: Brown adipose tissue

\section{Metabolism and control of energy expenditure: a cooperation between cytoplasm and oxidative organelles leading to catabolism}

Living cells comprise complex energy-producing and energy-utilising chemical reactions termed metabolism. Energy expenditure is strongly dependent on the activities of metabolic pathways. The stimulation of energy expenditure is observed either during physical exercise or during periods committed to control of body temperature such as arousal of hibernators or adaptation to cold of nonhibernators. Whether energy expenditure can be activated sufficiently in response to food intake to buffer excess energy intake remains controversial.

Energy expenditure results from catabolism of Ccontaining molecules and ATP hydrolysis. Catabolism involves degradation of ingested foodstuffs or stored fuels such as carbohydrate, lipid and protein. Catabolic pathways operate in the cytoplasm (glycolysis, pentose phosphate pathway), mitochondria (fatty acid oxidation, re-oxidation of reduced coenzymes), lysosomes (oligosaccharide degradation, protein degradation) and peroxysomes (degradation of fatty acids). The catabolic pathways split C-containing molecules such as glucose and fatty acids or amino acids into small molecules such as pyruvate, acetyl-CoA precursors and intermediary substrates of the tricarboxylic acid cycle, and generate reduced coenzymes (NADH, FADH ${ }_{2}$ ). Concomitantly, catabolic reactions promote ADP phosphorylation and ATP synthesis, since the reactions in metabolic pathways contributing to energy expenditure are exergonic reactions coupled to endergonic reactions. However, such reactions are clearly catabolic, as the coupling of exergonic and endergonic reactions is far below $100 \%$ and most synthesised ATP molecules are hydrolysed.

\section{Contribution of mitochondria to energy expenditure}

Although mitochondria are involved in urea synthesis, gluconeogenesis, $\mathrm{Ca}$ homeostasis, radical production, protein 
synthesis and apoptosis, their major function is cellular respiration and oxidation of reducing equivalents. These organelles contain two compartments bounded by inner and outer membranes. The outer membrane is permeable to small metabolites whereas the permeability of the inner membrane is strongly controlled. This inner membrane possesses specific transporters for ADP-ATP exchange, phosphate, pyruvate, oxoglutarate, citrate, glutamate and malate. The inner membrane maintains a high electrochemical gradient generated by the respiratory chain (see Nicholls \& Ferguson, 2002).

Mitochondria participate in energy expenditure through fatty acid oxidation and oxidation of reduced NADH and $\mathrm{FADH}_{2}$. In fact, the final steps of oxidation of fatty acids, carbohydrates and amino acids result in the formation of $\mathrm{NADH}$ and $\mathrm{FADH}_{2}$. The electron transport chain oxidises these reduced cofactors by transferring electrons in a series of steps to $\mathrm{O}_{2}$, which is the terminal electron acceptor. Simultaneously, the free energy of the oxidation-reduction reactions is used to drive ATP synthesis. This overall process is referred to as mitochondrial oxidative phosphorylation. The mechanism of coupling respiration to ADP phosphorylation was elucidated by Peter Mitchell (see Nicholls \& Ferguson, 2002). Complexes I, II and III of the respiratory chain pump protons to the outer surface of the inner membrane during re-oxidation and electron transfer. This proton pump generates a proton gradient that is made use of by mitochondrial ATP synthase. Thus, the ability of mitochondria to phosphorylate ADP to ATP limits the rate of respiration. Under such conditions a large proportion of oxidation energy is converted to ATP. However, the coupling of respiration to ATP synthesis is not $100 \%$ efficient and some of the energy is dissipated as heat. The partial coupling of respiration to ATP synthesis prevents the inhibition of respiration by exaggerated levels of ATP.

\section{Respiration uncoupling and energy expenditure: the example of the mitochondrial uncoupling protein 1 of brown adipose tissue}

Mitchell's theory predicted that any proton leak in the inner membrane not coupled with ATP synthesis would provoke the uncoupling of respiration and thermogenesis (see Nicholls \& Ferguson, 2002). Interestingly, this prediction has been validated by David Nicholls and by other researchers studying the thermogenic machinery of brown adipose tissue (Nicholls \& Locke, 1984; Ricquier \& Bouillaud, 2000; Cannon \& Nedergaard, 2004).

The brown adipose tissue is a particular form of adipose tissue found in infants at birth, rodents, small mammals and hibernators (Nicholls \& Locke, 1984; Kozak \& Harper, 2000; Ricquier \& Kozak, 2003; Cannon \& Nedergaard, 2004). In fact, the thermogenic activity of this organ has been observed at birth, during exposure to the cold or during arousal from hibernation. Brown adipocytes differ from white adipocytes by the presence of numerous mitochondria. These mitochondria exhibit a spontaneous uncoupling of respiration. Consequently, approximately $100 \%$ of the fatty acid oxidation is dissipated as heat instead, contributing to ATP synthesis. When brown adipocytes are activated, NEFA produced by the lipolysis of triacylglycerols activate a unique system of proton conductance present in the inner mitochondrial membrane. This system has been characterised as a specific membrane transporter termed uncoupling protein (UCP) and recently renamed UCP1. UCP1 belongs to the family of mitochondrial anion transporters that includes the adenine nucleotide translocator, the phosphate carrier, the citrate carrier, the oxoglutarate carrier and the acylcarnitine transporter (Kozak \& Harper, 2000; Ricquier \& Bouillaud, 2000; Ricquier \& Kozak, 2003).

The respiration-uncoupling activity and the thermogenic activity of UCP1 have been clearly demonstrated using different experimental approaches such as transport reconstitution in liposomes and inhibition or activation of its expression in cells or transgenic mice. UCP1 functions as a futile cycle, similarly to a shunt bypassing ATP synthase and making use of the electrochemical gradient. When UCP1 is functional, the utilisation of the proton gradient decreases the mitochondrial membrane potential, which in turn facilitates extrusion of protons and stimulates respiration (Nicholls \& Locke, 1984; Garlid \& Jaburek, 1998). Thermogenesis is associated with mitochondria and also results from a general activation of catabolic pathways in activated brown adipocytes.

\section{The mitochondrial uncoupling proteins 2 and 3}

The mitochondrial membrane transporters form a family comprising forty proteins. Recent studies have led to the identification of several proteins more similar to UCP1 than to other mitochondrial transporters and referred to as UCP2 and UCP3 (Kozak \& Harper, 2000; Ricquier \& Bouillaud, 2000; Boss et al. 2001; Ricquier \& Kozak, 2003). UCP2 and UCP3 are adjacent on human chromosome 11 and mouse chromosome 7 and may represent ancestral forms of UCP1. UCP2 and UCP3 share 58\% of their amino acid identity with UCP1 but differ markedly from the brown fat UCP as they have a different tissue distribution and physiological regulation. UCP1 is unique to brown adipocytes, UCP2 is expressed in numerous tissues, whereas UCP3 is predominantly expressed in skeletal muscles. It is also interesting that the expression of UCP2 or UCP3 is not induced during exposure to cold, in contrast to UCP1 expression. Another major difference between the three UCP is that UCP2 and UCP3 are normally expressed at a level that is 200-fold lower than that of UCP1 in brown adipocytes.

Despite many biochemical, genetic and physiological studies the exact functions of UCP2 and UCP3 remain unclear. Insertion of UCP2 or UCP3 in liposomes or their expression in cellular systems has led to conflicting data in relation to their proton-translocating activity and their respiration-uncoupling activity (Garlid \& Jaburek, 1998; Clapham et al. 2000; Garcia-Martinez et al. 2001; Klingenberg \& Echtay, 2001; Ledesma et al. 2002). Clapham et al. (2000) have reported that overexpression of UCP3 in skeletal muscle strongly decreases food efficiency in relation to the uncoupling of respiration. However, the same authors have also concluded that the uncoupling of respiration in these mice is artifactual (Cadenas et al. 2002). Analogous to the proposed role for UCP1, it has 
been suggested that the function of UCP3 could be to export excess fatty acids out of mitochondria in a situation of elevated mitochondrial fatty acid oxidation (Kozak \& Harper, 2000). It has also been proposed that UCP2 and UCP3 translocate either superoxide (Echtay et al. 2002) or fatty acid peroxides (Goglia \& Skulachev, 2003). UCP1 activity is strongly regulated by GDP (inhibition) and NEFA (activation). There is no consensus about the regulation of UCP2 and UCP3 by these ligands (Nègre-Salvayre et al. 1997; Garlid \& Jaburek, 1998; Couplan et al. 2002b; Krauss et al. 2002; Echtay et al. 2003). Echtay et al. (2002) and Krauss et al. (2002) have reported that superoxide is able to activate UCP1, UCP2 and UCP3. It has also been reported that ubiquinone contributes to the activation of the UCP (Klingenberg \& Echtay, 2001).

Studies of UCP2 or UCP3 variants have provided evidence both in support and against their contribution to diet-induced expenditure, body fat content, obesity or type 2 diabetes. Genetic studies have also suggested a role for the UCP2-UCP3 locus in resting metabolic rate (Bouchard et al. 1997) and anorexia nervosa ( $\mathrm{Hu}$ et al. 2002).

Most physiological studies have not enhanced the understanding of the roles of UCP2 and UCP3. These UCP do not contribute to the control of body temperature in response to the cold, and a study of Ucp2-/- and Ucp3-/mice receiving a high-fat diet has demonstrated that they do not contribute to diet-induced energy expenditure (Ricquier \& Kozak, 2003). Transgenic mice overexpressing a high and pharmacological level of UCP3 in their skeletal muscles are resistant to an obesity-inducing high-fat diet (Clapham et al. 2000). The metabolic roles of UCP2 and UCP3 are unclear, although nutritional and hormonal changes (starvation, high-fat diet, thyroid hormone status) have been shown to markedly alter UCP2 and UCP3 expression (Diehl \& Hoek, 1999; de Lange et al. 2001; Lanouette et al. 2001; Collins et al. 2002; Hesselink et al. 2003). It has been proposed that these transporters are involved in fatty acid metabolism and in metabolic adaptation linked to the transition from glucose oxidation to fatty acid oxidation (Dulloo \& Samec, 2001).

More specifically, UCP2 and UCP3 down regulate the mitochondrial production of reactive oxygen species (Ricquier \& Bouillaud, 2000) and UCP2 is a negative regulator of insulin secretion in response to glucose (Boss et al. 2001; Chan et al. 2004). Interestingly, these findings, derived from mice made null for $u c p 2$ or $u c p 3$, provide some support for respiration-uncoupling activity of UCP2 and UCP3. Based on the role of UCP2 in the limitation of reactive oxygen species and the relatively high level of UCP2 in macrophages it has been demonstrated that UCP2 protects against atherosclerosis (Alves-Guerra et al. 2003; Blanc et al. 2003). The importance of UCP2 in macrophages and in protection against atherosclerosis has been confirmed by Ryu et al. (2004). These authors have demonstrated that overexpression of UCP2 in monocytes inhibits trans-endothelial migration and adhesion to endothelial cells. A role for UCP2 in protection against chronic inflammatory diseases has been suggested (Pecqueur et al. 2001). Whether UCP2 directly affects levels of reactive oxygen species, or regulates glutathione, which in turn affects the levels of reactive oxygen species, has been the subject of discussion (de Bilbao et al. 2004). More recently, several studies (Bechmann et al. 2002; Clavel et al. 2003; Mattiasson et al. 2003; Paradis et al. 2003; Sullivan et al. 2003) have indicated a role for UCP2 in neuroprotection, while Ibrahim et al. (2000) have suggested that UCP2 contributes to autoimmune encephalomyelitis. It has also been reported that mice deficient in UCP3 are protected from hyperthermia induced by the drug N-methylD-aspartate (Mills et al. 2003). Other proposed roles for UCP2 are: activation of NO production (Kizaki et al. 2002); regulation of apoptosis (Voehringer et al. 2000; Teshima et al. 2003); activation of oncosis (Mills et al. 2002). Table 1 summarises the demonstrated and proposed roles of the UCP.

\section{Can induction or activation of uncoupling proteins stimulate fatty acid oxidation and promote energy expenditure?}

The chemical uncoupler of respiration, 2-4-dinitrophenol, has in the past been prescribed in the treatment of obese patients. The effects of such a toxin have been dramatic and extremely negative. It has severe metabolic effects and causes hyperpyrexia and death. An interesting observation, referred to as the Luft syndrome (Luft, 1992), has been reported. A patient was found to exhibit a catabolic state characterised by hypermetabolism of non-thyroid origin and a defect in the maintenance of mitochondrial respiratory control in skeletal muscle. Although the molecular mechanism was not identified, this observation highlights the contribution of respiration uncoupling to increased energy expenditure.

Following the characterisation of the brown adipocyte UCP, the ectopic expression of this UCP has been directed either to white adipose tissue or skeletal muscle of transgenic mice (Kopecky et al. 1995; Kozak \& Harper, 2000). As expected, these animals develop a resistance to dietinduced obesity. In particular, the expression of UCP1 in skeletal muscles induces a marked uncoupling of respiration and a stimulation of fatty acid oxidation (Li et al. 2000). However, UCP1 expression in skeletal muscles also modifies the ratio between the subtypes of muscular fibres and increases the proportion of type IIa oxidative fibres at the expense of glycolytic type IIb fibres (Couplan et al. $2002 a$ ). As mentioned earlier, transgenic mice overexpressing UCP3 in their skeletal muscles are also resistant to diet-induced obesity and type 2 diabetes (Clapham et al. 2000). However, in this study the amount of UCP3 was very large, and it seems improbable that such a level of induction can be obtained using any pharmacological approach.

More recently, Tiraby and colleagues (Tiraby \& Langin, 2003; Tiraby et al. 2003) have reported the induction of UCP1 in differentiating cultured human white adipocytes. Instead of using an expression vector for UCP1, they tried to obtain a physiological expression of UCP1 using transfection of preadipocytes by an adenoviral expression vector encoding the co-activator PPAR $\gamma$ co-activator-1. A moderate induction of UCP1 and mitochondrial proteins was observed. Interestingly, such a small induction of UCP1 was shown to result in a doubling of the oxidation of 
Table 1. Demonstrated and proposed roles for the mitochondrial uncoupling proteins (UCP) 1,2 and 3

\begin{tabular}{|c|c|c|c|}
\hline & UCP1 & UCP2 & UCP3 \\
\hline Biochemical role & $\begin{array}{l}\text { Proton transport }{ }^{\star} \\
\text { Export of deprotonated fatty acids } \\
\text { Transport of ROS }\end{array}$ & $\begin{array}{l}\text { Proton transport } \\
\text { Export of deprotonated fatty acids } \\
\text { Transport of ROS } \\
\text { Glutathione transport } \\
\text { Translocation of peroxidised fatty acids }\end{array}$ & $\begin{array}{l}\text { Proton transport } \\
\text { Export of deprotonated fatty acids } \\
\text { Transport of ROS } \\
\text { Translocation of peroxidised } \\
\text { fatty acids }\end{array}$ \\
\hline$x^{2}$ & $\begin{array}{l}\text { NEFA* } \\
\text { Retinoic acid } \\
\text { Superoxide } \\
\text { Ubiquinone } \\
\text { Hydroxynonenal }\end{array}$ & $\begin{array}{l}\text { NEFA } \\
\text { Retinoic acid } \\
\text { Superoxide } \\
\text { Ubiquinone } \\
\text { Hydroxynonenal }\end{array}$ & $\begin{array}{l}\text { NEFA } \\
\text { Superoxide } \\
\text { Ubiquinone } \\
\text { Hydroxynonenal }\end{array}$ \\
\hline Inhibitor & GDP, GTP, ADP, ATP* & GDP, ATP & GDP, ATP \\
\hline Physiological role & $\begin{array}{l}\text { Cold-induced thermogenesis* } \\
\text { Diet-induced thermogenesis }\end{array}$ & $\begin{array}{l}\text { Resting metabolic rate } \\
\text { Adaptation to increased fatty acid } \\
\text { oxidation } \\
\text { Limitation of ROS* } \\
\text { Control of NO* } \\
\text { Regulation of glutathione level } \\
\text { Protection against atherosclerosis* } \\
\text { Inhibition of insulin secretion* } \\
\text { Neuro-protection* } \\
\text { Anti-inflammatory activity } \\
\text { Inhibition of macrophage adhesion* } \\
\text { Apoptosis regulation } \\
\text { Oncosis activation }\end{array}$ & $\begin{array}{l}\text { Resting metabolic rate } \\
\text { Adaptation to increased fatty acid } \\
\text { oxidation } \\
\text { Limitation of ROS* } \\
\text { NMDA-induced hyperthermia* }\end{array}$ \\
\hline
\end{tabular}

ROS, reactive oxygen species; NMDA, N-methyl-D-aspartate. *Demonstrated roles for mitochondrial UCP.

palmitic acid by human adipocytes. It was also observed that the administration of PPAR $\gamma$ co-activator-1adenovirus to the inguinal fat map of mice induces UCP1 expression. These data suggest that a moderate induction of UCP1 in white fat may be used to increase metabolic energy expenditure in obese human subjects. Thus, specific uncoupling of adipocyte mitochondria remains an attractive target for the development of anti-obesity drugs.

\section{References}

Alves-Guerra MC, Rousset S, Pecqueur C, Mallat Z, Blanc J, Tedgui A, Bouillaud F, Cassard-Doulcier AM, Ricquier D \& Miroux B (2003) Bone marrow transplantation reveals the in vivo expression of the mitochondrial uncoupling protein 2 in immune and non immune cells during inflammation. Journal of Biological Chemistry 278, 42307-42312.

Bechmann I, Diano S, Warden CH, Bartfai T, Nitsch R \& Horvath TL (2002) Brain mitochondrial uncoupling protein 2 (UCP2): a protective stress signal in neuronal injury. Biochemical Pharmacology 64, 363-367.

Blanc J, Alves-Guerra MC, Esposito B, Rousset S, Gourdy P, Ricquier D, Tedgui A, Miroux B \& Mallat Z (2003) Protective role of uncoupling protein 2 in atherosclerosis. Circulation 107, 388-390.

Bouchard C, Perusse L, Chagnon YC, Warden C \& Ricquier D (1997) Linkage between markers in the vicinity of the uncoupling protein 2 gene and resting metabolic rate in humans. Human Molecular Genetics 11, 1887-1889.

Boss O, Hagen T \& Lowell BB (2001) Uncoupling proteins 2 and 3: potential regulators of mitochondrial energy metabolism. Diabetes 49, 143-156.
Cadenas S, Echtay KS, Harper JA, Jekabsons MB, Buckingham JA, Grau E, Abuin A, Chapman H, Clapham JC \& Brand MD (2002) The basal proton conductance of skeletal muscle mitochondria from transgenic mice overexpressing or lacking uncoupling protein-3. Journal of Biological Chemistry 277, 2773-2778.

Cannon B \& Nedergaard J (2004) Brown adipose tissue: function and physiological significance. Physiological Reviews 84, 277-359.

Chan CB, Saleh MC, Koshkin V \& Wheeler MB (2004) Uncoupling protein 2 and islet function. Diabetes 53, S136-S142.

Clapham C, Arch JR, Chapman H, Haynes A, Lister C, Moore GB et al. (2000) Mice overexpressing human uncoupling protein-3 in skeletal muscle are hyperphagic and lean. Nature 406, 415-418.

Clavel S, Paradis E, Ricquier D \& Richard D (2003) Kainic acid upregulated uncoupling protein-2 mRNA expression in the mouse brain. Neuroreport 14, 2015-2017.

Collins P, Bing C, McGulloch P \& Williams G (2002) Muscle UCP-3 mRNA levels are elevated in weight loss associated with gastrointestinal adenocarcinoma in humans. British Journal of Cancer 86, 372-375.

Couplan E, Gelly C, Goubern M, Fleury C, Quesson B, Silberberg M et al. (2002a) High level of uncoupling protein 1 expression in muscle of transgenic mice selectively affects muscles at rest and decreases their IIb fiber content. Journal of Biological Chemistry 277, 43079-43088.

Couplan E, Gonzalez-Barroso MM, Alves-Guerra MC, Ricquier D, Goubern M \& Bouillaud F (2002 b) No evidence for a basal, retinoic or superoxide-induced uncoupling activity of the UCP2 present in spleen or lung mitochondria. Journal of Biological Chemistry 277, 26268-26275.

de Bilbao F, Arsenijevic D, Vallet P, Hjelle OP, Ottersen OP, Bouras C et al. (2004) Resistance to cerebral ischemic injury 
in UCP2 knockout mice: evidence for a role of UCP2 as a regulator of mitochondrial glutathione levels. Journal of Neurochemistry 89, 1283-1293.

de Lange P, Lanni A, Beneduce L, Moreno M, Lombardi A, Silvestri E \& Goglia F (2001) Uncoupling protein-3 is a molecular determinant for the regulation of resting metabolic rate by thyroid hormone. Endocrinology 142, 3414-3420.

Diehl AM \& Hoek JB (1999) Mitochondrial uncoupling: Role of uncoupling protein anion carriers and relationship to thermogenesis and weight control 'The benefits of losing control'. Journal of Bioenergetics and Biomembranes 31, 493-505.

Dulloo AG \& Samec S (2001) Uncoupling proteins: their roles in adaptive thermogenesis and substrate metabolism reconsidered. British Journal of Nutrition 86, 123-139.

Echtay KS, Esteves TC, Pakay JL, Jekabsons MB, Lambert AJ, Portero-Otin M, Pamplona R, Vidal-Puig AJ, Wang S, Roebuck SJ \& Brand MD (2003) A signalling role for 4-hydroxy-2-nonenal in regulation of mitochondrial uncoupling. EMBO Journal 22, 4103-4110.

Echtay KS, Roussel D, St-Pierre J, Jekabsons MB, Cadenas S, Stuart JA, Harper JA, Roebuck SJ, Morrison A, Pickering S, Clapham JC \& Brand MD (2002) Superoxide activates mitochondrial uncoupling proteins. Nature 415, 96-99.

Garcia-Martinez C, Sibille B, Solanes G, Darimont C, Mace K, Villaroya F \& Gomez-Foix AM (2001) Overexpression of UCP3 in cultured human muscle lowers mitochondrial membrane potential, raises ATP/ADP ratio, and favors fatty acid vs. glucose oxidation. FASEB Journal 11, 2033-2035.

Garlid KD \& Jaburek M (1998) The mechanism of proton transport mediated by mitochondrial uncoupling proteins. FEBS Letters 438, 10-14.

Goglia F \& Skulachev VP (2003) A function for novel uncoupling proteins: antioxidant defense of mitochondrial matrix by translocating fatty acid peroxides from the inner to the outer membrane leaflet. FASEB Journal 17, $1585-1591$.

Hesselink MKC, Greenhaff PL, Constantin-Teodosiu D, Hultma E, Saris WHM, Nieuwlaat R, Schaart G, Kornips E \& Schrauwein P (2003) Increased uncoupling protein 3 content does not affect mitochondrial function in human skeletal muscle in vivo. Journal of Clinical Investigation 111, 479-486.

Hu X, Murphy F, Karwautz A, Li T, Giotakis O, Treasure J \& Collier DA (2002) Analysis of microsatellite markers at the UCP2/UCP3 locus on chromosome 11q13 in anorexia nervosa. Molecular Psychiatry 7, 814.

Ibrahim SM, Mix E, Böttcher T, Koczan D, Gold R, Rolfs A \& Thiesen HJ (2000) Gene expression profiling of the nervous system in murine experimental autoimmune encephalomyelitis. Brain 124, 1927-1938.

Kizaki T, Suzuki K, Hitomi Y, Taniguchi N, Saitoh D, Watanabe K, Onoe K, Day NK, Good RA \& Ohno H (2002) Uncoupling protein 2 plays an important role in nitric oxide production of lipopolysaccharide-stimulated macrophages. Proceedings of the National Academy of Sciences USA 99, 9392-9397.

Klingenberg M \& Echtay KS (2001) Uncoupling proteins: the issues from a biochemist point of view. Biochimica et Biophysica Acta 1504, 128-143.

Kopecky J, Clarke G, Enerback S, Spielgelman B \& Kozak LP (1995) Expression of the mitochondrial uncoupling protein gene from the ap2 gene promoter prevents genetic obesity. Journal of Clinical Investigation 96, 2914-2923.
Kozak LP \& Harper ME (2000) Mitochondrial uncoupling proteins in energy expenditure. Annual Review of Nutrition 20, 339-363.

Krauss S, Zhang CY \& Lowell BB (2002) A significant portion of mitochondrial proton leak in intact thymocytes depends on expression of UCP2. Proceedings of the National Academy of Sciences USA 99, 118-122.

Lanouette CM, Giacobino JP, Perusse L, Lacaille M, Yvon C, Chagnon M, Kuhne F, Bouchard C, Muzzin P \& Chagnon YC (2001) Association between uncoupling protein 3 gene and obesity-related phenotypes in the Quebec Family Study. Molecular Medicine 7, 433-441.

Ledesma A, de Lacoba MG \& Rial E (2002) The mitochondrial uncoupling proteins. Genome Biology 3, 3015.1-3015.9.

Li B, Nolte LA, Ju JS, Han DH, Coleman T, Holloszy JO \& Semenkovich CF (2000) Skeletal muscle respiratory uncoupling prevents diet-induced obesity and insulin resistance in mice. Nature Medicine 6, 1115-1120.

Luft R (1992) Luft's disease revisited. Severe hypermetabolism of nonthyroid origin with a defect in the maintenance of mitochondrial respiratory control. Mount Sinai Journal of Medicine 59, 140-145.

Mattiasson G, Shamloo M, Gido G, Mathi K, Tomasevic G, Yi S, Warden $\mathrm{CH}$, Castilho RF, Melcher T, GonzalezZulueta M, Nikolich K \& Wieloch T (2003) Uncoupling protein-2 prevents neuronal death and diminishes brain dysfunction after stroke and brain trauma. Nature Medicine $\mathbf{9}$, 1062-1068.

Mills EM, Banks ML, Sprague JE \& Finkel T (2003) Pharmacology: uncoupling the agony from ecstasy. Nature 426, 403-404.

Mills EM, Xu D, Fergusson MM, Combs CA, Xu Y \& Finkel T (2002) Regulation of cellular oncosis by uncoupling protein 2. Journal of Biochemical Chemistry 277, 27385-27392.

Nègre-Salvayre A, Hirtz C, Carrera G, Cazenave R, Troly M, Salvayre R, Penicaud L \& Casteilla L (1997) A role for uncoupling protein-2 as a regulator of mitochondrial hydrogen peroxide generation. FASEB Journal 11, 809-815.

Nicholls DG \& Ferguson SL (2002) Bioenergetics. Amsterdam: Academic Press.

Nicholls DG \& Locke R (1984) Brown fat thermogenesis. Physiological Reviews 64, 1-64.

Paradis E, Clavel S, Bouillaud F, Ricquier D \& Richard D (2003) Uncoupling protein-2: a novel player in neuroprotection. Trends in Molecular Medicine 9, 522-525.

Pecqueur C, Alves-Guerra MC, Gelly C, Levi-Meyrueis C, Couplan E, Collins S, Ricquier D, Bouillaud F \& Miroux B (2001) Uncoupling protein 2, in vivo distribution, induction upon oxidative stress, and evidence for translational regulation. Journal of Biological Chemistry 276, 8705-8712.

Ricquier D \& Bouillaud F (2000) The uncoupling protein homologues: UCP1, UCP2, UCP3, StUCP \& AtUCP. Biochemical Journal 345, 161-179.

Ricquier D \& Kozak LK (2003) Uncoupling proteins. In Handbook of Obesity, pp. 539-558 [GA Bray and C Bouchard, editors]. New York: Marcel Dekker Inc.

Ryu JW, Hong KH, Maeng JH, Kim JB, Ko J, Park JY, Lee KU, Hong MK, Park SW, Kim YH \& Han KH (2004) Overexpression of uncoupling protein 2 in THP1 monocytes inhibits beta2 integrin-mediated firm adhesion and transendothelial migration. Arteriosclerosis, Thrombosis and Vascular Biology 24, 864-870.

Sullivan PG, Dube C, Dorenbos K, Steward O \& Baram TZ (2003) Mitochondrial uncoupling protein-2 protects the 
immature brain from excitotoxic neuronal death. Annals of Neurology 53, 711-717.

Teshima Y, Akao M, Jones SP \& Marban E (2003) Uncoupling protein-2 overexpression inhibits mitochondrial death pathway in cardiomyocytes. Circulation Research 93, 192-200.

Tiraby C \& Langin D (2003) Conversion from white to brown adipocytes: a strategy for the control of fat mass? Trends in Endocrinology and Metabolism 14, 439-441.
Tiraby C, Tavernier G, Lefort C, Larrouy D, Bouillaud F, Ricquier D \& Langin D (2003) Acquirement of brown fat cell features by human white adipocytes. Journal of Biological Chemistry 278, 33370-33376.

Voehringer DW, Hirschberg DL, Xiao J, Lu Q, Roederer M, Lock CB, Herzenberg LA, Steinman L \& Herzenberg LA (2000) Gene microarray identification of redox and mitochondrial elements that control resistance or sensitivity to apoptosis. Proceedings of the National Academy of Sciences USA 97, 2680-2685. 